\title{
Study and Application on Security Technology of Computer Information System
}

\author{
Yan Liu \\ College of Information Engineering of Haikou College of Economics, Haikou 571127, China \\ 857630@qq.com
}

\begin{abstract}
Keywords: Computer information system, security technology, computer information system, network information security.
\end{abstract}

\begin{abstract}
In this paper, the secure policy on application of the computer information system, the secure principle, secure layer, secure service and secure architecture model of the development of computer information system are mainly studyed on this thesis. The developing situation both home and abroad about computer information system security is indroducecd in this thesis. Thenetwork security, database security, cipher technology,firewall technology are researched .The secure policy and measures on the application and development of the computer information system are analyzed.The system design, database design, main system module fuction on a science and research MIS as the instance are explained in detail about, which is built as a complicated secure information system according to the secure layer and architecture model of the computer information system .Besides, the optimization of application system and database system are deeply discussed .The conclusions are given at the end of the thesis.
\end{abstract}

\section{Introduction}

With the development of the information technology, computer information system has played an important role in modern society. As long as any break appears in computer information system, it takes a huge effect in whole society. There is an important, direct and realistic significance in research about computer system security [1].

With the scale of computer information system (CIS) expanding and the security technology developing, a systematic and normalized computer information system security architecture (CISSA) is needed to strengthen the design, development, implementation, evaluation and management of CISSA. [2] In order to normalize the build of CISSA, and construct the security defense architecture in our country, a uniform CISSA model and the implementer standard must be built.

The computer information systems security assessment of our country has just been started. In order to meet the needs of the development of Computer information systems risk assessment, my main purposes of the study are shown as follows:

1 .Research on standards, work out a reasonable standard criteria. Under this standard, all the computer information systems have the same traceability of testing and evaluation. And they have the certain comparability.

2. Against this standard, I try to sum up an assessment method. The method can be operated and can be actually used. Make the work of computer information system security risk assessment from the theoretical level standards extend to the practical application of the quantitative examination. Make the work of computer information system security risk assessment from the requirements of the standard on the actual assessment extend to the analysis of the technical point.

\section{The model frame and risk assessment}

On the basis of studying and researching abroad standards, reference and summed up CC on the model of information security framework. We developed the information system security assessment framework. System function module is shown in Fig. 1. As the computer information systems risk assessment standards, this standard is divided into three parts: Engineering, Technology and 
Management. [3] According to the three parts of the security environment, determined security target, proposed security requirements, achieved information systems security. Technology standard reference to the CC, divided into 11 classes: Security audit, Communication, Cryptographic support, User data protection, Identification and authentication, Securitymanagement, Privacy, Protection of the TSF, Resource utilization, TOE access, Trusted path/channels. Management standard reference to the BS7799, divided into 12 classes: Risk management, Information security policy, Information security organizations, Person security, Asset management, Physical and environmental security, Compliance management, Information security planning, System development, Operation, Business continuity and disaster recovery, Emergency response. [4] Engineering standard which refers to SSE-CMM and other international standards, is divided into: Risk process, System definition, Threat assessment, Vulnerability assessment, Security risk assessment, Engineering process, Determine security requirements, High-level safety design, Detailed safety design, Security project, Provide a safe input, Surveillance security situation, Management of security control, Security Coordination, Support process, Verification and validation of safety, Evidence establishing guarantee. Each class has put forward detailed operational subassembly with the structure of the CC. Each subassembly has a different corresponding class which satisfies the safety requirements.

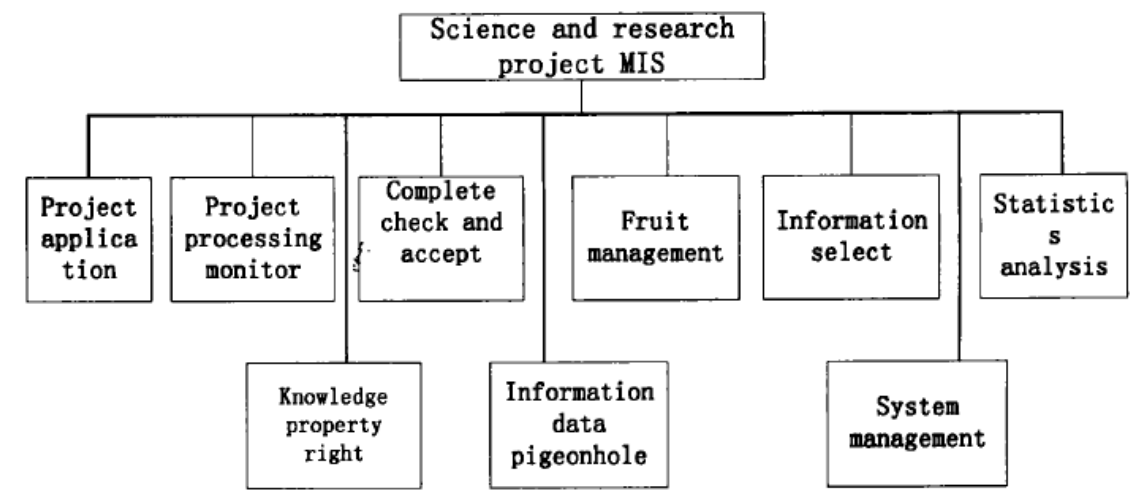

Fig. 1 System function module

Information system entity security is that measures which are adopted to ensure all sorts of equipment of information system and environmental establishment. It includes the securities of place, facility, power supply, air condition and purifying, electromagnetism shield, information storing medium.

Information system technological security is that technological means which is adopted in information system to prevent the system resource from illegal using and store. The security of information resource includes dynamic and static. Dynamic security is that control measures which is used during the course of access data information. Static security is the encryption measure during the transportation and storing information.

\section{Security architecture construction of information system}

The security of the information system is a matter of system, past experience and lessons indicate that if not considering establishing the system of safety standard of information system, it will often cause such problems as incompleteness of the whole function, some weakness parts, redundant of part function, low efficiency, difficultly assessing, not adapting demand and technology change, difficultly operating each other. [5] With the constant enlargement of the scale of computer information system and constant development of the information security technology, in order to strengthen the design, development, use, assessment and management of the security system of computer information system, the security system of computer information system should be systematized understood and be carried on standardized construction. Therefore, it is necessary to set up the unified security system model of computer information system and implementation standard, standardize the security system construction of the computer information system, and then build the security counter measures system of computer information system in our country. 
Secure structural model of information system can embody through three-dimensional space, which is shown as Fig. 2. A kind of secure service can be provided by a kind or kinds of secure countermeasure and A kind of countermeasure can be provided by a kind or kinds of secure services. Sorts of secure countermeasure can process in one layer or more layer of the information system when they provide secure service.

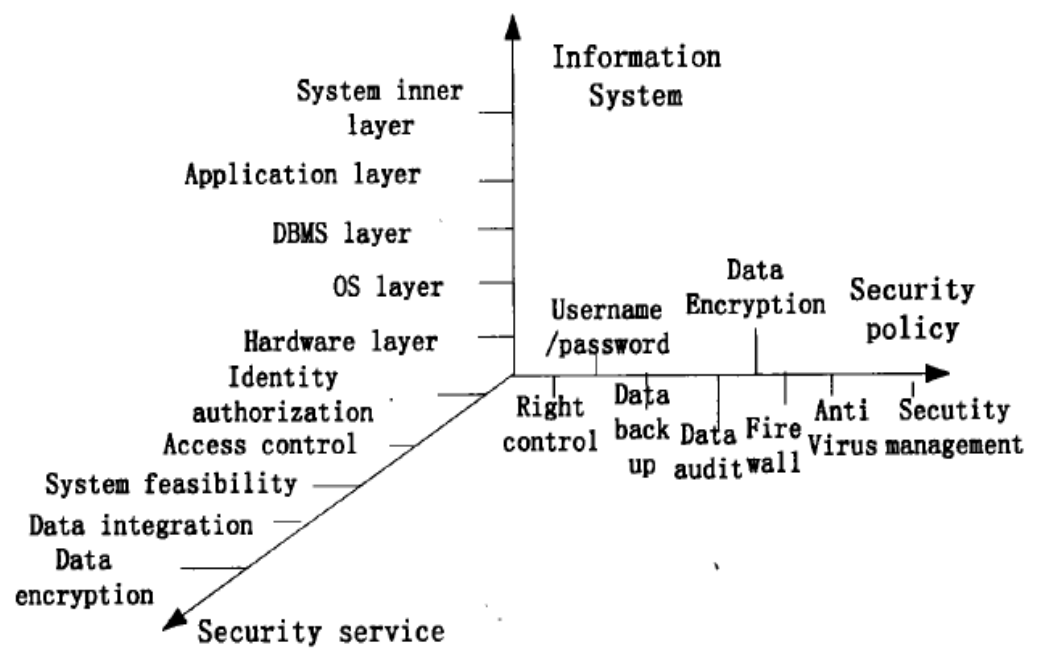

Fig. 2 Secure structure model of information system

\section{Secure policy of information system development}

It is a balance to build a secure computer system in a series of requirement. Secure principle must avoid all sorts of factors as possible in order to affect other systematical trait. [6] When security contradict other nature such as network transport rate, it should be accept or abandon according to its essentiality to system. Principles which are built in system are as follow:

Take security as a kind of requirement and make it be considered in the begin of systematical development. Security is acted as dominant position during the systematical development.

Make use of all kinds of secure mechanism in the different systematical layer and implement different accurate secure control. At the same time, reduce the secure relativity of different layer in order to assure the reliability and feasibility. Especially, A special nature which should be attentioned to is access control of different level user in the course of secure design of application software.

Adopt reasonable secure technology and secure granularity so that system become a balance between the security and other nature. These nature include capability, efficiency, agility, friendly interface, cost and so on.

When security is not consistent with other nature, all sorts of rules can be established to make up for the technological shortage. When consider the systematical efficiency especially in $\mathrm{B} / \mathrm{S}$, it may not be encrypted except user password and key data in application layer.

First, it should enhance the important awareness of Secure problem of the computer information system. Second, it should strengthen information security and information secret management institution so that the law and rules about information security can rapidly and effectively carry out.

Finally, build computer information security specialized service organ, strengthen the social essurence of computer network system and information security. Increase research strength on secure technology of the computer information system .Aim at setting up secure run architecture of the computer information system and research technology,environmentan, management and so on. Strengthen propagation and enhance the social secure consciousness. 


\section{Alarm information code}

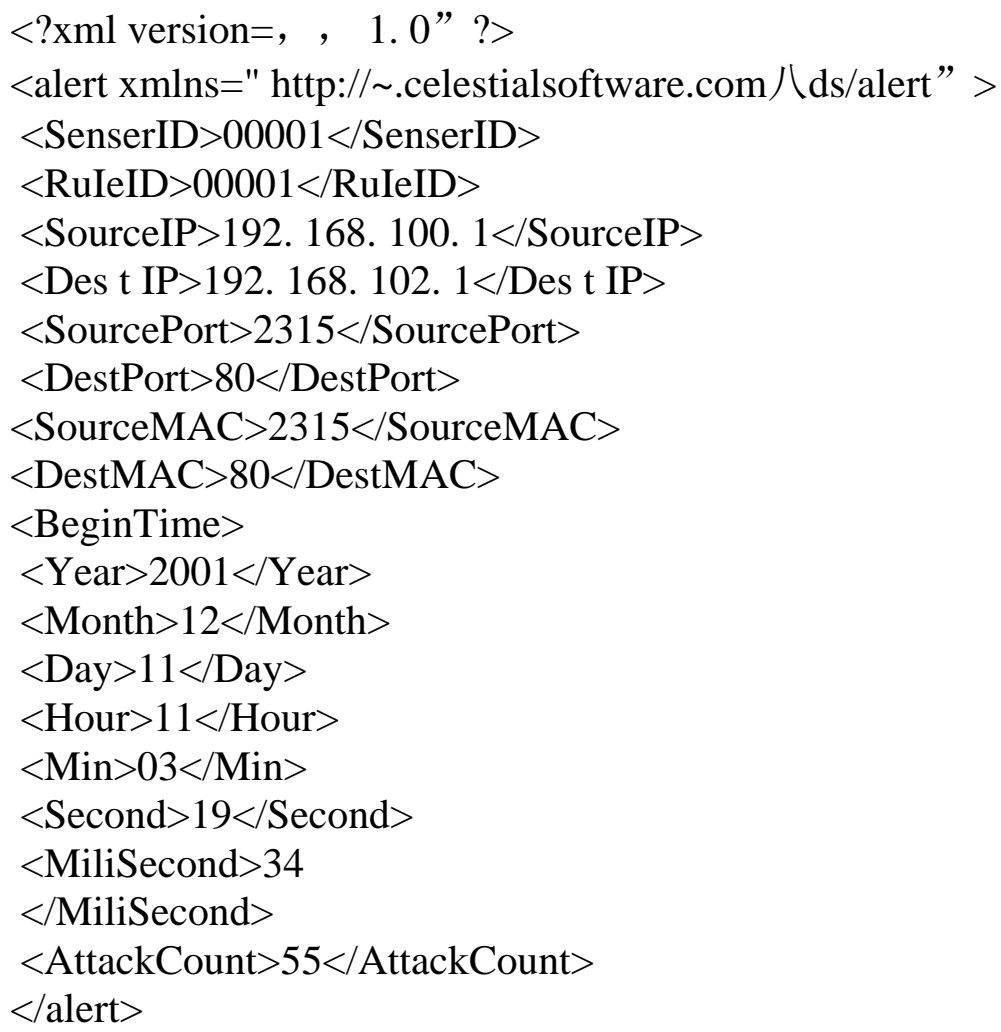

\section{Conclusions}

With the rapid development of the information age the computer and the Internet are more and more people use and dependence orb computer system has gradually become a people living and working in a big pillar Once the computer system is destroyed all in order to survival of the people or institutions will collapse to ensure all people working and living a normal lift computer information system security protection measures is essential about computer information system security technology research subject form any $m$ any approaches have been applied to the security protection of computer inform anon system in.

\section{References}

[1] Greg Elofson, Peggy M Beranek, Philomina Thomas. An intelligent agent community approach to knowledge sharing. Decision Support System, 2012, (20): 83-98.

[2] R.S. Sandhu, et al. Role-Based Access Control Models. IEEE Computer, 2012, 29(2): 38-47.

[3] Stuart McClure, Joel Scambray, George Kurtz. Hacking Exposed Fifth Edition:Network Security Secrets \& Solutions. New York:McGraw-Hill, 2014, (9): 13-15.

[4] D. F Ferraiolo, R. Sandhu, S. GavriIa, D. R. Kuhn R. Chandramouli. Proposed NIST standard forrole-based access control. ACM Transactions on Information and System Security, 2013, 4(3): 224-274.

[5] Andrew S, Tanenbaum. Computer Networks. 3rd Ed. Prentice Ha11, 2006 (5): 26-33.

[6] Neuman C, Kerberos T. An authentication. Service for computer networks Communication Magazine, 2010, 32(9): 33-38. 